\title{
The Absence of HCV RNA and NS5A Protein in Peripheral Blood Mononuclear Cells Is a Prognostic Tool for Sustained Virological Response
}

\author{
Azhar Mehmood,,2 Muhammad Javaid Asad, Muhammad Ovais,, Nasib Zaman, \\ Hafsa Aziz, Javaid Irfan,, Irshad Ahmad, and Abida Raza, ${ }^{1, *}$
}

\begin{abstract}
Hepatitis C Virus (HCV) infection is a major health concern worldwide. The presence of both HCV viral RNA and NS5A proteins in peripheral blood mononuclear cells (PBMCs) indicate the efficacy of the treatment during sustained virological response (SVR) and end of treatment response (ETR). The main objective of this study was to detect the absence or presence of HCV RNA and NS5A proteins in PBMCs. Blood samples were taken from selected patients (Islamabad, Pakistan) before treatment, at ETR, and during SVR. Two hundred HCV responders to pegylated IFN- $\alpha$-2a plus ribavirin were selected. HCV RNA was extracted from the patients to determine the viral load by reverse transcription (RT)-polymerase chain reaction before treatment. Out of 200 patients, $152(76 \%)$ and $48(24 \%)$ achieved positive and negative ETR, respectively. Among ETR patients, 134 $(88.2 \%)$ showed SVR, whereas $18(11.8 \%)$ displayed relapse. The male to female ratio was 92:108 with mean age of 37.4 years. Among 152 ETR-positive patients, 29 (19\%) patients' PBMCs were positive for HCV RNA and $27(17.8 \%)$ were positive for NS55A proteins. Patients having HCV RNA in PBMCs showed higher relapse frequency compared with patients lacking it. Similarly, patients having NS5A protein showed significantly higher relapse frequency compared with patients lacking it. All PBMC-positive samples were of genotype 3a. In addition, patients with positive NS5A in their PBMCs showed greater risk of relapse compared with patients having HCV RNA. We conclude that the absence of both viral HCV and proteins can be used as an indicator for diagnosis of SVR in the future.
\end{abstract}

Keywords: hepatitis $\mathrm{C}$ virus, pegylated IFN- $\alpha-2 \mathrm{a}$, ribavirin, peripheral blood mononuclear cells, end of treatment response

\section{Introduction}

$\mathbf{H}$ EPATITIS C VIRUs (HCV) is a worldwide predominant pathogen, which is a major cause of liver disease (10). Current estimates of disease burden shows an upturn in seroprevalence over the last 15 years to $2.8 \%$, equating to $>185$ million infections worldwide (14). HCV infection for a prolonged period is linked with the development of liver cirrhosis, hepatocellular cancer, and liver failure, ultimately causing death of the patient (21). HCV is an enveloped, positive-sense, single-stranded RNA virus that belongs to the genus Hepacivirus and family Flaviviridae (23). After the first report of $\mathrm{HCV}$ genome, it was obvious that isolates from different geographic regions will show a significant genetic diversity (9). HCV is classified into seven genotypes. Within each genotype, it is further classified into 67 confirmed and 20 provisional subtypes (27). Genotypes 1 and 2 are primarily in West Africa, 3 in South Asia, 4 in Central Africa and the Middle East, 5 in Southern Africa, and 6 in South East Asia (28). Recently a new HCV genotype 7 has been reported; it was isolated in Canada from a Central African immigrant (24).

\footnotetext{
${ }^{1}$ Nuclear Medicine, Oncology, and Radiotherapy, Institute NORI, Islamabad, Pakistan.

${ }^{2}$ Department of Biochemistry, PMAS-Arid Agriculture University, Rawalpindi, Pakistan

${ }^{3}$ Department of Life Sciences, King Fahd University of Petroleum and Minerals (KFUPM), Dhahran, Saudi Arabia.

*Present affiliation: National Institute for Lasers and Optronics (NILOP), Islamabad, Pakistan.
} 
Table 1. Polymerase Chain Reaction Analysis CyCling CONDITIONS For Viral LOAD DETERMination of Peripheral Blood Mononuclear Cells Hepatitis C Virus RNA-Positive Samples

\begin{tabular}{lcl}
\hline Cycles & Temperature $\left({ }^{\circ} \mathrm{c}\right)$ & \multicolumn{1}{c}{ Time } \\
\hline Hold 1 & 50 & $30 \mathrm{~min} \mathrm{0} \mathrm{sec}$ \\
Hold 2 & 95 & $15 \mathrm{~min} \mathrm{0} \mathrm{sec}$ \\
(50 repeats) & & \\
Step 1 & 95 & $30 \mathrm{sec}$ \\
Step 2 & 50 & $60 \mathrm{sec}$ \\
Acquiring to cycling (green, orange) & \\
Step 3 & 72 & $30 \mathrm{sec}$ \\
\hline
\end{tabular}

Sustained virological response (SVR) is defined as the absence of HCV RNA in patient's serum or plasma, 6 months after the completion of therapy. Interleukin (IL)-28 gene polymorphism, low level viremia at baseline level, age and gender distribution, and HCV genotype are important factors that stimulate the SVR $(3,29)$. The presence of $\mathrm{HCV}$ RNA in peripheral blood mononuclear cells (PBMCs) among individuals with negative serum HCV RNA is an indicator of viral relapse (11) especially among immunocompromised individuals having long-term treatment, other viral infections, or surgery cases. In such patients virus might reactivate in the future. Similarly, it acts as a reservoir for extrahepatic expressions of HCV infection. The extrahepatic replication of HCV RNA has been studied in the peripheral mononuclear cells that act as a reservoir for HCV RNA replication (7). Among SVR patients, the replication rate in the liver cells has been found to be higher than in PBMCs (19).

The presence of HCV RNA in PBMCs was considered as a proof of replication that acts as a replicative intermediate in the extrahepatic cells. It is the lymphotropic nature of $\mathrm{HCV}$ RNA that plays an important role in viral persistence and infection in PBMCs (16). PBMC is the privileged location for $\mathrm{HCV}$, where they reactivate after the completion of treatment when conditions become more favorable implying that even if $\mathrm{HCV}$ eradication from hepatocyte is attained, reinfection from PBMC may occur (extrahepatic site). Nonstructural protein 5A (NS5A) is a proline-rich hydrophilic phosphoprotein, which plays a key role in HCV replication (5). NS5A is translated from HCV genome, whereas its posttranslation modification is carried out by nonstructural protein 3 (NS3) viral protease. Therefore, NS5A plays a major role in multiple HCV infection stages $(15,17)$.

The current study has been designed around HCV responders that were given pegylated IFN- $\alpha$-2a plus ribavirin treatment to detect the presence of HCV-RNA and NS5A protein in PBMCs as an indicator for SVR. Other parameters, such as viral load and alanine amino transferase (ALT) in blood, were also studied in early virological responder (EVR) and SVR patients in the presence of PBMCs. This study will highlight the prognostic role of viral RNA in SVR and relapse, with a view to verifying the importance of HCV-RNA and NS5A protein in PBMCs to be developed for diagnostic purpose and used as an indicator for devising antiviral therapy for hepatitis C-infected patients.

\section{Materials and Methods}

\section{Patient enrollment}

This was an interventional study conducted from March 2013 to April 2014 at The Nuclear Medicine Oncology and Radiotherapy Institute (NORI) Islamabad, Pakistan.

\section{Selection criteria}

All patients were selected according to the following criteria. HCV genotype 3a-infected patients of both genders were selected. Immunocompromised, children, coinfected, and pregnant patients were excluded from the study. Approved consent was taken on a predesigned performa from the participating individuals. Approval of the study was obtained from the Ethics Committee of NORI.

\section{Blood parameters estimation}

Three to five milliliters of blood was collected from each patient. Different blood parameters of $\mathrm{HCV}$ responder patients were tested. Hemoglobin, platelets, and white blood cells were determined with Sysmex XP 100 (KOBE-Japan), whereas ALT was estimated from serum by using COBAS e 411 (Roche).

\section{IFN- $\alpha-2 a$ plus ribavirin treatment}

The participating individuals received antiviral combination therapy with Pegylated IFN-2a $(180 \mu \mathrm{g})$ once a week and ribavirin $(800-1200 \mathrm{mg}$ ) according to the patient's body weight

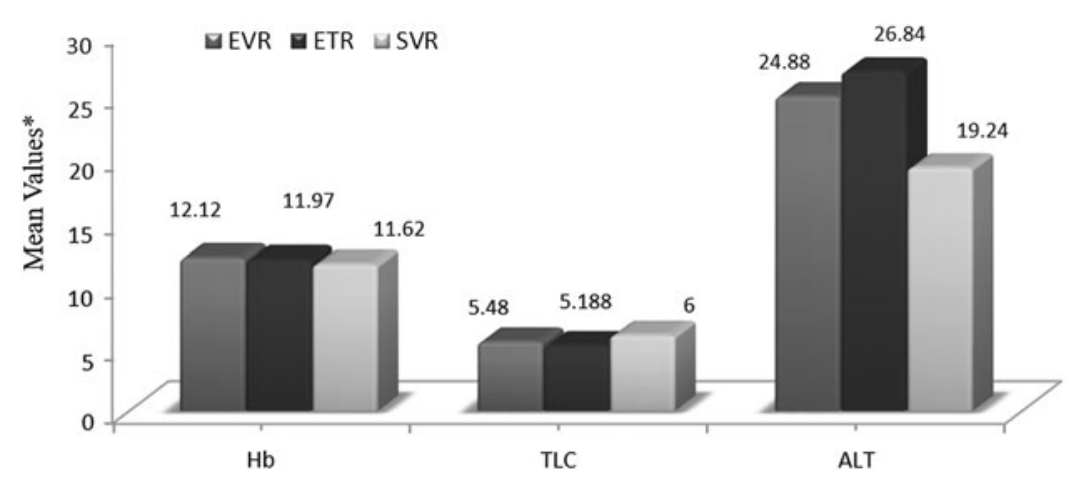

FIG. 1. Comparison of mean values of various blood parameters among different groups of HCV responders. *The respective units for $\mathrm{Hb}, \mathrm{TLC}$, and platelets are in $\mathrm{g} / \mathrm{dL}, \mathrm{g} / \mu \mathrm{L}$, and $\mathrm{U} / \mathrm{L}$, respectively. ETR, end of treatment response; EVR, early virological responder; $\mathrm{HCV}$, hepatitis $\mathrm{C}$ virus; TLC, total leukocyte count. 


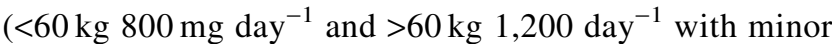
modifications based on age and complete blood analysis). The therapy is given for a period of 24 weeks followed by collection of blood samples for the determination of end of treatment response (ETR). For the confirmation of SVR stage, blood samples were collected after 6 months of completion of therapy. The procedures carried out for patient's selection and antiviral therapy were in accordance with the American Association for the Study of Liver Diseases (AASLD) Practice Guidelines (22).

\section{Viral load determination}

HCV viral load was determined by RNA extraction unit, KingFisher ${ }^{\circledR} \mathrm{mL}$ (Thermo Electron Corporation, Finland) using the Instant Virus RNA Extraction Kit (AJ Roboscreen, Berlin, Germany). The RoboGene ${ }^{\circledR}$ HCV RNA Quantification Kit was used for the amplification of extracted viral RNA using TaqMan chemistry on Rotor Gene 3000 ${ }^{\mathrm{TM}}$ (Corbett Research, Australia). Various fluorescence reporter dyes were used for the independent measurement of RNA for example, HCV RNA:FAM, internal positive control RNA:Yakima Yellow. FAM and JOE channels were utilized for acquiring data. Polymerase chain reaction (PCR) conditions were according to the reported protocol of AJ Roboscreen (Table 1). The quantitative range for assay was $3-5 \times 10^{9}$ copies per run, with a detection limit of 3 synthetic HCV RNA molecules per PCR run.

\section{Isolation and detection of HCV-RNA in PBMCs}

PBMCs were isolated by Ficoll reagent method using RPMI media for washing. RNA was extracted by TRI Reagent method from PBMCs of $\mathrm{HCV}$ responder patients. Extracted RNA was stored at $-80^{\circ} \mathrm{C}$ for further experiments. RNA was converted into cDNA for HCV genotyping by previously reported method (25). Regular PCR cycles were run to produce double-stranded DNA followed by nested PCR for further amplification. Nested PCR product was run on $2 \%$ agarose gel and the analysis was performed on Gel documentation system (Bio-Rad).

The following primers were designed using GenBank sequence (Accession No. D10749) for the amplification of HCV 5' UTR

Forward: 5' GAGTGTCGTGCAGCCTGGA 3'

Reverse: 5' CACTCGCAAGCACCCTATCA 3'

$5^{\prime}$ (FAM) CCCGCAAGACTGCTAGCCGAGTAGTGTT GG (TAMRA) 3'

\section{Utilization of immunofluorescence assay for detection of HCV NS5A proteins in PBMCs}

HCV NS5A protein in PBMCs was detected with minor modification as described in earlier methods $(30,31)$. PCMCs suspension in RPMI-1640 media was adjusted to $1 \times 10^{6}$ cells/ mL. PBMCs were fixed in $4 \%$ paraformaldehyde for $14 \mathrm{~min}$ followed by washing (three times) with buffer and centrifugation $(300 \mathrm{~g})$. The fixed PBMCs were treated with primary antibodies (MAB8694; Merck Millipore) specific for HCV virus NS5A region followed by an incubation period of 25 min. After washing, PBMCs were treated with fluorescein isothiocyanate-conjugated secondary antibodies, for $20 \mathrm{~min}$. Final washing was carried out for the removal of unbound secondary antibodies followed by staining of cell nuclei with
TABle 2. Comparison of VArious Blood Parameters Among Naive Versus Early Virological Responders, EARLY VIROLOGICAL RESPONDERS VERSUS END

of Treatment Response, and END of Treatment RESPONSE Versus Sustained Virological RESPONSE PATIENTS

\begin{tabular}{lccc}
\hline & \multicolumn{2}{c}{ Paired differences } & \\
\cline { 2 - 3 } & \multicolumn{2}{c}{ 95\% Confidence } \\
& interval difference & \\
\cline { 2 - 3 } & Lower & $\mathrm{p}$ \\
\hline Naive vs. EVR & \multicolumn{1}{c}{ Upper } & \\
Hb & 0.6959 & 1.7641 & 0.000 \\
TLC & 12.10072 & 1714.55648 & 0.047 \\
Platelet & -46187.526 & 15515.806 & 0.323 \\
ALT & 16.925 & 64.712 & 0.001 \\
EVR vs. ETR & & & \\
Hb & 0.0905 & 0.8175 & 0.015 \\
TLC & -115.0021 & 542.9581 & 0.197 \\
Platelet & -15736.1927 & 46954.9887 & 0.322 \\
ALT & -8.941 & 13.370 & 0.691 \\
ETR vs. SVR & & & \\
Hb & -0.6739 & -0.0690 & 0.017 \\
TLC & -541.76457 & 291.37641 & 0.549 \\
Platelet & -45.1164 & -3.8183 & 0.021 \\
ALT & -2.121 & 23.978 & 0.098 \\
\hline
\end{tabular}

ALT, alanine amino transferase; ETR, end of treatment response EVR, early virological responders; SVR, sustained virological response; TLC, total leukocyte count.

4'6-diamidino-2-phenylindole (DAPI). Zeiss LSM 510 laser confocal microscopy module was used for immunofluorescence observation of the stained cells.

\section{Statistical analysis}

Data were analyzed using SPSS Ver. 20 and GraphPad Prism 5. A $p$-value of less than 0.05 was considered to be statistically significant with a confidence interval (CI) of $95 \%$, odds ratio (OR), positive predictive values, and negative predictive value.

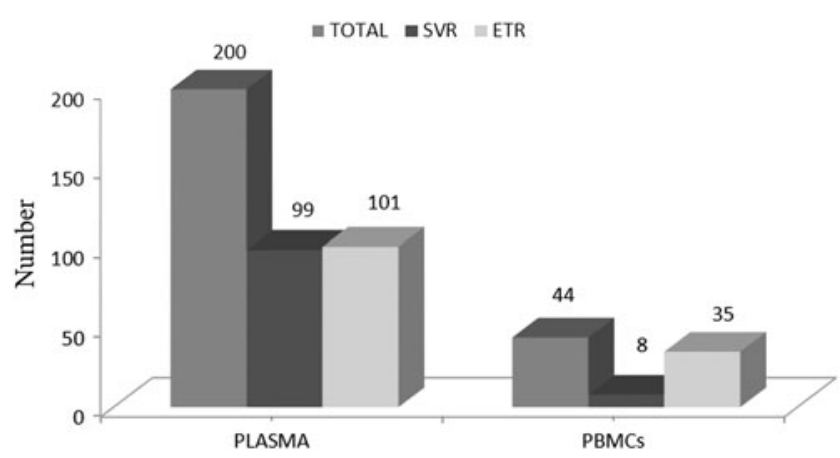

FIG. 2. This figure shows the detection of HCV RNA in plasma and isolated PBMCs of the patients in various groups of $\mathrm{HCV}$ responder patients. PBMCs, peripheral blood mononuclear cells. 
Table 3. Hepatitis C Virus Rna Detection in Peripheral Blood Mononuclear Cells at End of Treatment Response Associated with Sustained Virological Response in Treated Patients

\begin{tabular}{lcccccc}
\hline Group & SVR & Relapse & Chi-square & OR & $\mathrm{p}$ & $95 \%$ CI \\
\hline PBMC negative, 123(80.9\%) & $112(91.1 \%)$ & $11(8.9 \%)$ & & & & \\
PBMC positive, 29 (19.1\%) & $22(75.9 \%)$ & $7(24.1 \%)$ & 5.2 & 3.2 & 0.04 & $1.131-9.280$ \\
Total, 152 & $134(88.2 \%)$ & $18(11.8 \%)$ & & & & \\
\hline
\end{tabular}

CI, confidence interval; OR, odds ratio; PBMC, peripheral blood mononuclear cell.

\section{Results}

\section{Studying various blood parameters among different groups of $\mathrm{HCV}$ responders}

This is an interventional study conducted by the outpatient's department of NORI, Islamabad, Pakistan from March 2013 to April 2014. Our cohort predominantly consisted of female patients $108(54 \%)$ with mean age of subjects 37.4 years. Minimum age limit was 19 years, whereas maximum age limit was 58 years. The comparison of blood parameters between different groups are presented in Figure 1, whereas the statistical correlation of blood parameters between different groups of HCV responders is shown in Table 2. Mean $\mathrm{Hb}$, total leukocyte count (TLC), platelets, and ALT values were $13.1 \mathrm{~g} / \mathrm{dL}$, $7.6 \times 10^{3} / \mu \mathrm{L}, \quad 248.3 \times 10^{3} / \mu \mathrm{L}$, and $76.7 \mathrm{U} / \mathrm{L}, \quad$ respectively, whereas at EVR stage, the mean for $\mathrm{Hb}$, TLC, platelets, and ALT were determined as $12.1 \mathrm{~g} / \mathrm{dL}, 5.4 \times 10^{3} / \mu \mathrm{L}, 245.2 \times 10^{3} /$ $\mu \mathrm{L}$, and $33.8 \mathrm{U} / \mathrm{L}$, respectively. After the completion of the therapy, the $\mathrm{Hb}$, TLC, platelet, and ALT mean values were $11.9 \mathrm{~g} / \mathrm{dL}, 5.1 \times 10^{3} / \mu \mathrm{L}, 229$, and $26.84 \mathrm{U} / \mathrm{L}$, respectively, whereas 6 months after the completion of therapy (SVR stage), the mean values were $11.6 \mathrm{~g} / \mathrm{dL}, 6 \times 10^{3} / \mu \mathrm{L}, 242.2 \times 10^{3} / \mu \mathrm{L}$, and $24 \mathrm{U} / \mathrm{L}$ for $\mathrm{Hb}$, TLC, platelets, and ALT, respectively.

\section{HCV RNA detection in PBMCs at ETR associated with SVR in treated patients}

In this study HCV RNA was detected by PCR in the plasma of $200 \mathrm{HCV}$ patients among which 101 and 99 were ETR and SVR responders, respectively. The PBMCs samples were used for the detection of HCV RNA and NS5A proteins (Fig. 2). A total of 152 patient's blood was tested

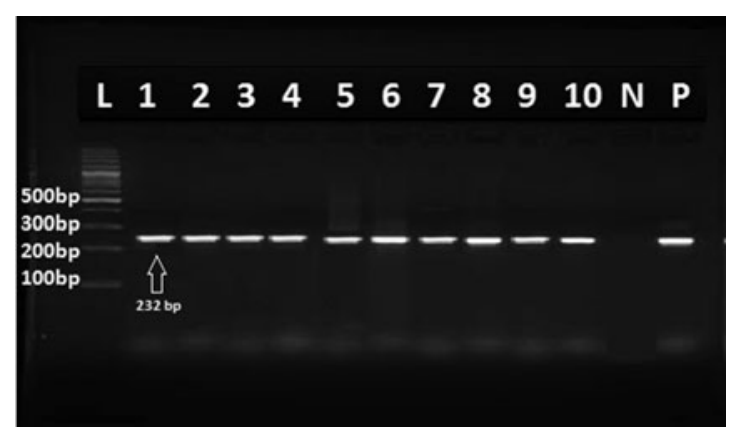

FIG. 3. The picture of the PCR product on the gel shows band of genotype $3 \mathrm{a}$ amplified product of HCV-RNA extracted from PBMCs. "L" indicates ladder of $100 \mathrm{bp}$. From 1 to 10 are PBMCs genotype 3 a samples of $232 \mathrm{bp}$. "N" indicates negative control, whereas " $\mathrm{P}$ " is for positive control. PCR, polymerase chain reaction. for the presence or absence of HCV RNA in PBMCs. In this group, HCV RNA was not detected in 123 (80.9\%) patients, $29(19.1 \%)$ of the PBMCs were HCV RNA negative. Moreover, $11(8.1 \%)$ showed relapse, whereas 112 (91.1) showed SVR. The patients whose PBMCs were HCV RNA positive $7(24.1 \%)$ showed relapse, whereas 22 $(75.8 \%)$ showed SVR. The patients who had detectable HCV RNA in immune cells comparatively showed higher relapse rate than those whose PBMCs were negative for HCV RNA $\left(24.1 \%\right.$ vs. $8.1 \%, \chi^{2}=5.2, \mathrm{OR}=3.2, p$-value $<0.05$, 95\% CI $=1.131-9.280$, Table 3$)$. These results implied that detection of HCV from serum or plasma is not a reliable predictor of SVR. Among ETR patients (plasma negative) $35(34.6 \%)$ out of 108 responders showed positive for RNA in their PBMCs. The genotyping results showed that all the PBMC-positive patients have HCV genotype $3 \mathrm{a}$, which is the most prevalent genotype in Pakistan (2) (Fig. 3).

\section{Comparison of various blood parameters among naive versus EVR, EVR versus ETR, and ETR versus SVR patients}

The comparison of $\mathrm{Hb}$, TLC, and ALT level between naive versus EVR group showed significant differences in levels with a $p$-value $<0.05$ as indicated in Table 2 . Whereas platelet count had a $p$-value greater than $0.05(0.323)$, which shows that the difference between platelet count among naive versus EVR group is nonsignificant. However, there might be slight variation due to other unknown factors. In the second group (EVR vs. ETR), Hb has a $p$-value $<0.05$, which suggests that there is a significant variation in $\mathrm{Hb}$ levels with time. The patient's Hb level decreased at the ETR stage. These differences might be due to different dosages of pegylated interferon (IFN) therapy. EVR patients were given fewer injections (less dosage) as compared with ETR patients. The other three factors (TLC, platelet, and ALT) showed nonsignificant $(p>0.05)$ difference among all the blood parameters during EVR as well as at the end of therapy, which demonstrates a positive sign that patients responded to the treatment. On the other hand, the third group constitutes ETR versus SVR. Data were compared on the basis of four different attributes $(\mathrm{Hb}$, ALT, TLC, and platelets). The results showed significant difference among $\mathrm{Hb}$ and platelet count having $p$-value $<0.05$, which illustrates that both $\mathrm{Hb}(p=0.017)$ and platelets $(p=0.021)$ had different values among ETR and SVR groups. The mean Hb level decreased, whereas platelet count increased in the SVR stage. This was due to IFN plus ribavirin therapy in ETR responders and the absence of such drugs in SVR group patients. However, 
Table 4. Viral Load Result of Various Peripheral Blood Mononuclear Cell-Positive Patients

\begin{tabular}{cccc}
\hline Serial No. & Type & Threshold cycle & Viral load $($ IU/mL) \\
\hline 1 & Sample & 19.7 & $3,389,324$ \\
2 & Sample & 24.1 & 177,456 \\
3 & Sample & 19.6 & $1,838,753$ \\
4 & Sample & 23.2 & 192,567 \\
5 & Sample & 21.5 & $1,823,452$ \\
6 & Sample & 25.4 & 162,213 \\
7 & Sample & 28.4 & 18,965 \\
8 & Sample & 22.4 & $1,645,678$ \\
9 & Sample & 26.4 & 15,223 \\
10 & Sample & 30.4 & 1,900 \\
11 & Sample & 19.4 & $1,845,345$ \\
QS1 & Standard & 20.6 & $1,834,723$ \\
QS2 & Standard & 24.0 & $1,834,723$ \\
QS3 & Standard & 27.4 & 18,987 \\
QS4 & Standard & 30.0 & 1,823 \\
\hline
\end{tabular}

${ }^{a}$ The analysis of resulting sigmoid growth curve (log scale) was done using the RG software 6.2 .25 with a slope value of -3.03 to -3.40 , (mean $-3.16 \pm 0.01$ ) and $R$ value of 0.9999 .

there might be other unknown reasons for this observation. The other two parameters (serum ALT level and the TLC) had $p$-value $>0.05$ suggesting that there was no significant change in ALT and TLC between the two response groups.

\section{Viral load determination in PBMC-positive patients}

The categorization of PBMCs RNA-positive patients $(n=44)$ was also carried out on the basis of viral load. The patients were categorized as highly positive (>800,000 IU/mL) $20(45.4 \%)$, positive ( $>20,000$ to $\leq 800,000 \mathrm{IU} / \mathrm{mL}) 12(27.2 \%)$, low-positive $(>8,000$ to $\leq 20,000 \mathrm{IU} / \mathrm{mL}) 11(25.1 \%)$, and very low-positive groups $(\leq 8,000 \mathrm{IU} / \mathrm{mL}) 1(2.2 \%)$. Table 4 gives the viral load with cycle threshold values of various PBMC-positive samples, whereas Figure 4 shows the graphical output of the PCR analysis in detail. The results showed that the detection of PBMCs RNA was found to be highest among the highly positive $(45.4 \%)$ patient group as compared with the low-positive patient group. This indicates that the patients with high viral load at the start of treatment were at greater risk of viral relapse as compared with patients having low titer of HCV-RNA.

\section{Association of HCV NS5A proteins in ETR responded patients with relapse rate}

The blood samples from all the patients were detected for HCV NS5A protein expression by using indirect immunofluorescence method. The association between HCV relapse in PBMCs is shown as in Table 5. In a total of 152 patients, PBMCs were tested for the presence of NS5A proteins. Out of these patients $(80.3 \%), 123$ were negative for NS5A proteins in which $7.4 \%$ (9) patients showed relapse and $92.6 \%$ (113) showed SVR. Similarly, in $19.7 \%$ (30) patients, PBMCs had detectable level of the protein in which $30 \%$ (9)
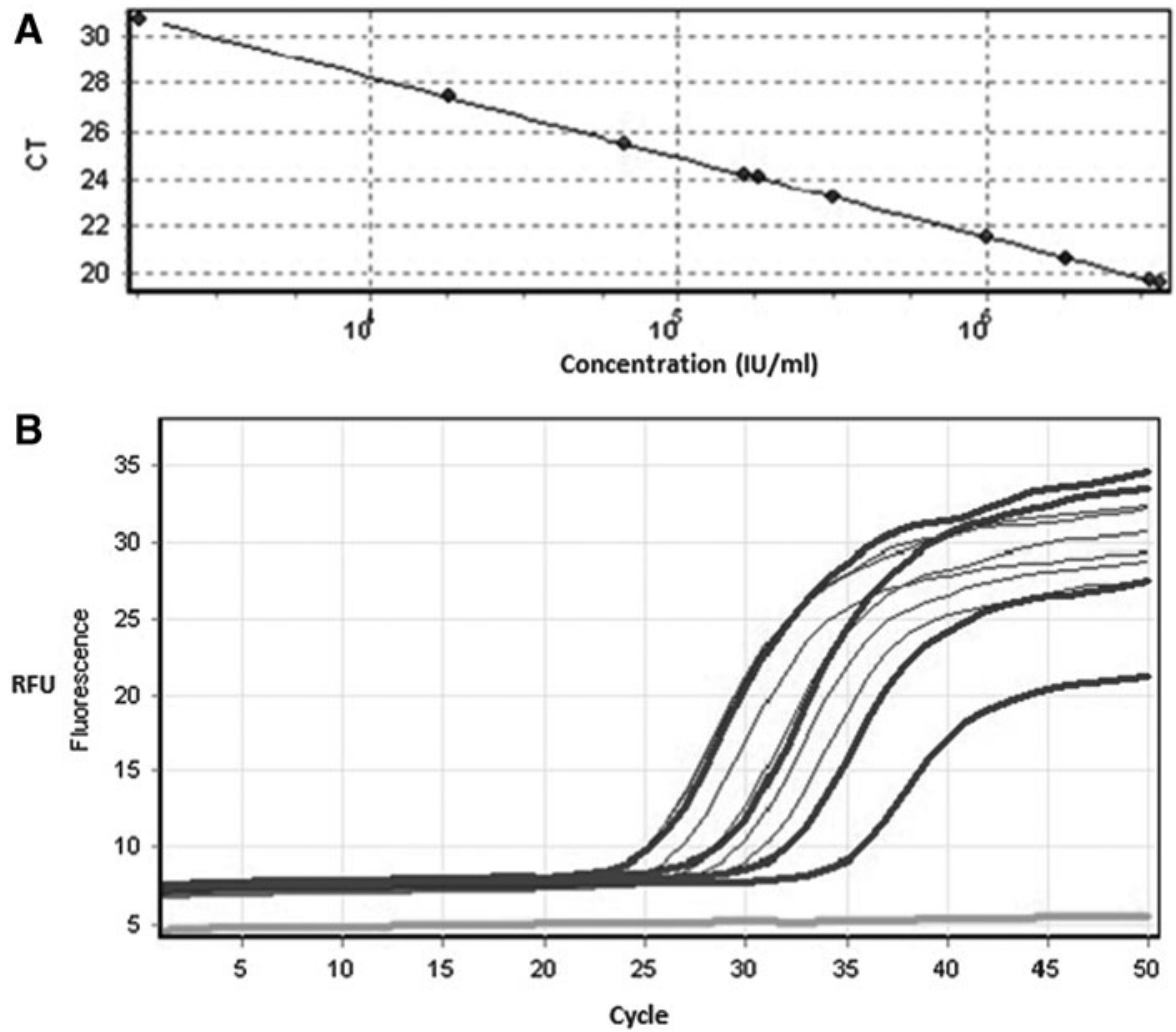

FIG. 4. The viral load analysis image of various PBMC-positive patients. (A) This image indicates the concentration of samples and standards used, on X-axis in IU/mL, whereas Y-axis indicates cycle threshold (CT value). (B) The thin peaks indicate samples, whereas the bold ones are of four standards. X-axis indicates the number of PCR cycles, whereas Y-axis shows the fluorescence emitted during the reaction in RFU. RFU, relative fluorescence units. 
Table 5. Association of Hepatitis C Virus NS5a Proteins in End of Treatment Response Responded Patients with Relapse Rate

\begin{tabular}{lcccccc}
\hline Group & SVR & Relapse & Chi-square & OR & $\mathrm{p}$ & $95 \%$ CI \\
\hline PBMC NS5A negative, 122 (80.3\%) & $113(92.6 \%)$ & $9(7.4 \%)$ & & & & \\
PBMC NS5A positive, 30 (19.7\%) & $21(70 \%)$ & $9(30 \%)$ & 11.8 & 5.3 & 0.00 & $1.912-15.15$ \\
Total, 152 & $134(88.2 \%)$ & $18(11.8 \%)$ & & & & \\
\hline
\end{tabular}

showed relapse and $70 \%$ (21) patients showed SVR response. The patients whose immune cells had viral proteins showed significantly higher relapse as compared with patients whose PBMCs had no viral proteins (30\% vs. $7.4 \%$; $\left.\chi^{2}=11.8, \mathrm{OR}=5.3, p=0.00,95 \% \mathrm{CI}=1.912-15.15\right)$. The protein was mostly found in the cytoplasm (Fig. 5). The negative control image of PBMCs is shown in Figure 6, which lacks HCV NS5A protein expression. These results indicate that PBMCs may be the main extrahepatic reservoirs for HCV protein translation.

\section{Discussion}

The presence of both HCV viral RNA and NS5A proteins in PBMCs shows the effectiveness of the treatment during SVR and ETR. B cells, T cells, macrophages, and monocytes were among PBMCs population reported among $\mathrm{HCV}$-infected individuals (4). It was found that HCV infection was supported by human B and T cell lines (20).
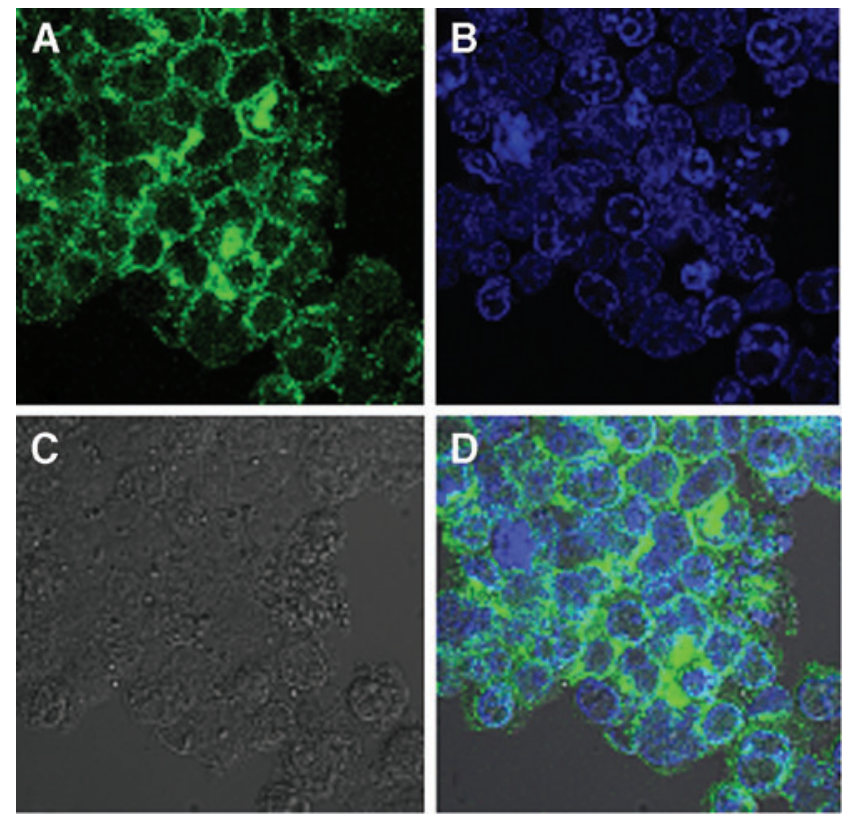

FIG. 5. This figure shows the visual representation for the detection of HCV NS5A protein in infected PBMCs. Different patterns of the same image have been shown in various emission formats. (A) Emission of Green fluorescence is of HCV NS5A. (B) Blue signal is of DAPI used for staining the nuclei of cells. In (C) black and white format of the image is shown, whereas (D) shows the overall emission spectra for HCV NS5A (green) and nuclei of cells (blue). Observation of cells was performed under confocal microscope with magnification of 70×. DAPI, 4'6-diamidino-2-phenylindole. Color images available online at www.liebertpub.com/vim
PBMCs are an important component of the immune system and are associated with both innate immune responses as well as adaptive immune responses (26). In a current report, HCV RNA has been detected in the PBMCs of SVR patients (16). It was found that 12 out of 55 patients $(21 \%$ responder's having negative serum HCV RNA) were HCV RNA positive in their PBMCs. In another study, quasispecies distribution in PBMCs was described as an important factor in achieving genetic variation among individual groups (6). It is important for the assessment, evaluation, and effectiveness of the treatment. It helps in planning the dosage and expected duration of the treatment.

There are various sources of HCV transmission such as injectable drug users (IDUs), body piercing, barber, dentistry, surgery, blood transfusion, and sexual transmission. Among PBMCs, RNA-positive patients $(n=44)$, IDUs 14 $(31.8 \%)$ were ranked highest and regarded as the most common source of $\mathrm{HCV}$ transmission followed by dentistry $11(25 \%)$, piercing $9(20.4 \%)$, barber $4(9.0 \%)$, surgery 4 $(9.0 \%)$, and blood transfusion $2(4.5 \%)$. These results clearly indicate that IDUs were at high risk of viral relapse. According to an estimate, the number of IDUs in Pakistan is $\sim 5$ million and $15 \%$ of them are regular drug users (18). A study from Pakistan on IDUs indicates that majority of the users wanted to get rid of the addiction, but could not
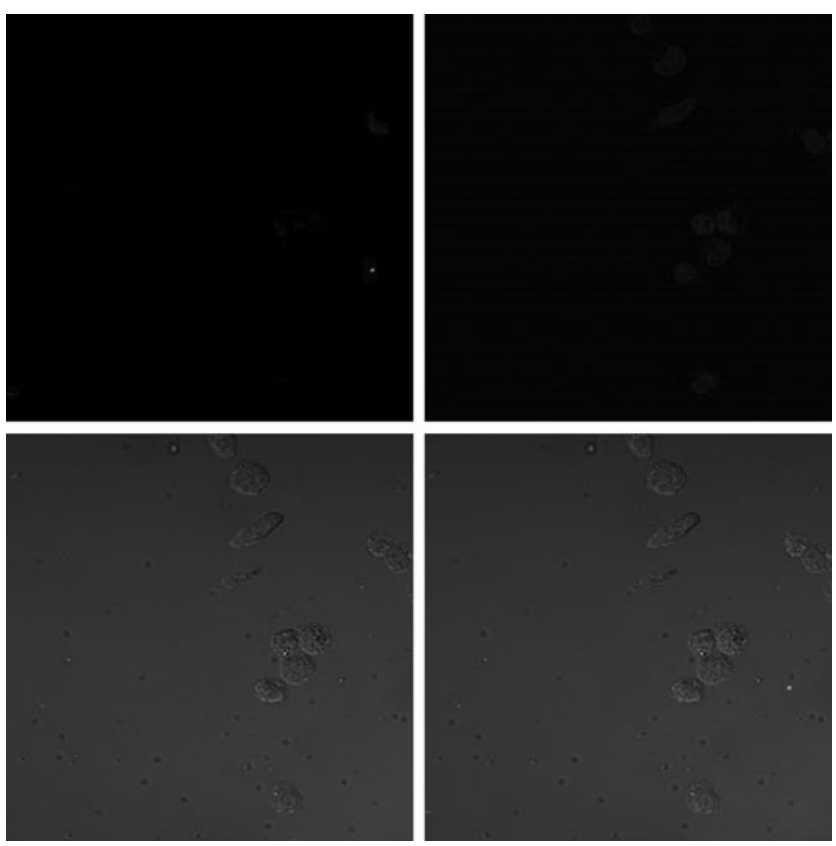

FIG. 6. Negative control image of PBMCs showing lack of HCV NS5A protein expression. Image is taken by confocal microscope with magnification range of $70 \times$. 
do so due to nonavailability or high charges by rehabilitation centers (1).

In the current study, the PBMCs RNA was found to be highest among the highly positive $(45.4 \%)$ patient group as compared with the low-positive patient group. This shows that the patients having high viral load at the start of treatment were at a greater risk of viral relapse as compared with patients having low titer of HCV-RNA, which is in conformity with previously reported studies $(8,12)$. Immunocytochemical staining technique was previously reported by our group for the detection of nonstructural proteins in PBMCs of local population (31). Additionally, our previous study showed that HCV actively replicates in PBMCs due to the accumulation of viral proteins in $30.6 \%$ of SVR patients, whereas in this study we have found that $28.2 \%$ of SVR patients were positive for HCV NS5A protein expression (31). The reliability of indirect immunofluorescence assay plus the presence of NS5A protein in the cytoplasm is consistent with the previous findings (13). The presence of NS5A under confocal microscopy clearly indicates that this protein binds with the plus and minus strand of HCV RNA and regulates the host cell function and activities.

\section{Conclusion}

The absence of HCV RNA or NS5A in plasma and the presence of these in isolated PBMCs indicated that PBMCs may act as a reservoir for HCV. Detection of HCV RNA and NS5A protein in PBMCs may be an additional diagnostic tool for hepatitis $\mathrm{C}$ patients. In the future, extensive studies should be carried out on the role of IL-28 gene in SVR patients and research can be designed on exploring the capability of NS5A in regulating the interferon response of host cells in the local population.

\section{Acknowledgments}

The authors highly appreciate and acknowledge the provision of laboratory facilities by NORI. The personal assistance of IA by KFUPM is acknowledged. The authors are thankful to K.S. Siddiqui for editing the article.

\section{Author Disclosure Statement}

No competing financial interests exist.

\section{References}

1. Altaf A, Janjua NZ, and Hutin Y. The cost of unsafe injections in pakistan and challenges for prevention program. J Coll Physicians Surg Pak 2006;16:622-624.

2. Attaullah S, Khan S, and Ali I. Hepatitis C virus genotypes in Pakistan: a systemic review. Virol J 2011;8:433.

3. Aziz H, Raza A, Ali K, et al. Polymorphism of the IL28B gene (rs8099917, rs12979860) and virological response of Pakistani hepatitis $C$ virus genotype 3 patients to pegylated interferon therapy. Int J Infect Dis 2015;30:91-97.

4. Bain C, Fatmi A, Zoulim F, et al. Impaired allostimulatory function of dendritic cells in chronic hepatitis $\mathrm{C}$ infection. Gastroenterology 2001;120:512-524.

5. Belda O, and Targett-Adams P. Small molecule inhibitors of the hepatitis $\mathrm{C}$ virus-encoded NS5A protein. Virus Res 2012;170:1-14.
6. Blackard JT, Ma G, Welge JA, et al. Analysis of a nonstructural gene reveals evidence of possible hepatitis $\mathrm{C}$ virus (HCV) compartmentalization. J Med Virol 2012;84: 242-252.

7. Cavalheiro NDP, Filgueiras TC, Melo CE, et al. Detection of HCV by PCR in serum and PBMC of patients with hepatitis C after treatment. Braz J Infect Dis 2007;11: 471-474.

8. Chary A, Winters MA, Eisen R, et al. Quantitation of hepatitis $\mathrm{C}$ virus RNA in peripheral blood mononuclear cells in $\mathrm{HCV}$-monoinfection and $\mathrm{HIV} / \mathrm{HCV}$-coinfection. $\mathbf{J}$ Med Virol 2012;84:431-437.

9. Choo Q, Kuo G, Weiner A, et al. Isolation of a cDNA clone derived from a blood-borne non-A, non-B viral hepatitis genome. Science 1989;80:359-362.

10. Cooke GS, Lemoine M, Thursz M, et al. Viral hepatitis and the Global Burden of Disease: a need to regroup. J Viral Hepat 2013;20:600-601.

11. De Marco L, Gillio TA, Fiano V, et al. Occult HCV infection: an unexpected finding in a population unselected for hepatic disease. PLoS One 2009;4:e8128.

12. Dichamp I, Abbas W, Kumar A, et al. Cellular activation and intracellular HCV load in peripheral blood monocytes isolated from HCV monoinfected and HIV-HCV coinfected patients. PLoS One 2014;9:e96907.

13. Gong GZ, Lai LY, Jiang YF, et al. HCV replication in PBMC and its influence on interferon therapy. World $\mathbf{J}$ Gastroenterol 2003;9:291-294.

14. Hanafiah KM, Groeger J, Flaxman AD, et al. Global epidemiology of hepatitis $C$ virus infection: new estimates of age-specific antibody to HCV seroprevalence. Hepayology 2013;57:1333-1342.

15. He Y, Staschke KA, and Tan SL. HCV NS5A: a multifunctional regulator of cellular pathways and virus replication. Hepatitis C viruses: Genom Mol Biol 2006; 267-292.

16. Inglot M, Pawlowski T, Szymczak A, et al. Replication of hepatitis $\mathrm{C}$ virus in peripheral blood mononuclear cells in patients with chronic hepatitis $\mathrm{C}$ treated with pegylated interferon alpha and ribavirin. J Cover 2015;69.

17. Keyvani H, Fazlalipour M, Monavari SHR, et al. Hepatitis C virus-proteins, diagnosis, treatment and new approaches for vaccine development. Asian Pac J Cancer Prev 2012;13:59175935.

18. Kuo I, Galai N, Thomas D, et al. High HCV seroprevalence and HIV drug use risk behaviors among injection drug users in Pakistan. Harm Reduct J 2015;3:10.

19. Laskus T, Radkowski M, Piasek A, et al. Hepatitis $\mathrm{C}$ virus in lymphoid cells of patients coinfected with human immunodeficiency virus type 1: evidence of active replication in monocytes/macrophages and lymphocytes. J Infect Dis 2000;181:442-448.

20. Laskus T, Radkowski M, Wang LF, et al. Hepatitis C virus quasispecies in patients infected with HIV-1: correlation with extrahepatic viral replication. Virology 1998;248:164171.

21. Lauer GM, and Walker BD. Hepatitis $\mathrm{C}$ virus infection. $\mathrm{N}$ Engl J Med 2001;345:41-52.

22. Marc G, Ghany DBS, David LT, et al. AASLD practice guidelines. Diagnosis, management, and treatment of hepatitis C: an update. Hepatology 2009;49:1335-1374.

23. Moradpour D, Penin F, and Rice CM. Replication of hepatitis C virus. Nat Rev Microbiol 2007;5:453-463. 
24. Murphy DG, Sablon E, Chamberland J, et al. Hepatitis C virus genotype 7 , a new genotype originating from central Africa. J Clin Microbiol 2015;53:967-972.

25. Ohno O, Mizokami M, Wu RR, et al. New hepatitis $\mathrm{C}$ virus (HCV) genotyping system that allows for identification of HCV genotypes 1a, 1b, 2a, 2b, 3a, 3b, 4, 5a, and 6a. J Clin Microbiol 1997;35:201-207.

26. Roque-Afonso AM, Ducoulombier D, Di Liberto G, et al.: Compartmentalization of hepatitis $\mathrm{C}$ virus genotypes between plasma and peripheral blood mononuclear cells. J Virol 2005;79:6349-6357.

27. Smith DB, Bukh J, Kuiken C, et al. Expanded classification of hepatitis $\mathrm{C}$ virus into 7 genotypes and 67 subtypes: updated criteria and genotype assignment Web resource. Hepatology 2014;59:318-327.

28. Smith DB, Pathirana S, Davidson F, et al. The origin of hepatitis C virus genotypes. J Gen Virol 1997;78: 321-328.

29. Woitas RP, Petersen U, Moshage D, et al. HCV-specific cytokine induction in monocytes of patients with different outcomes of hepatitis C. World J Gastroenterol 2002;8: 562-566.

30. Zaman N, Asad MJ, Raza A, et al. Detection of HCV RNA and NS5A protein in peripheral blood mononuclear cells after sustained virological response may cause viral relapse. Pak J Zool 2015;47:981-987.

31. Zaman N, Asad MJ, Raza A, et al. Presence of HCV RNA in peripheral blood mononuclear cells may predict patients response to interferon and ribavirin therapy. Ann Saudi Med 2013;34:401-406.

Address correspondence to: Dr. Abida Raza

National Institute for Lasers and Optronics (NILOP) Atomic Energy Commission Islamabad 44000 Pakistan

E-mail: abida_rao@yahoo.com 